\title{
REVISITING THE URBAN DEFINITION FOR THE ISLAND OF MAURITIUS
}

\author{
BIBI NAJIAH KAUDEER \& SANTARAM VENKANNAH \\ Department of Mechanical Engineering, Faculty of Engineering, University of Mauritius, Mauritius
}

\begin{abstract}
Mauritius is a small island located in the south west of the Indian Ocean, about $900 \mathrm{~km}$ from the island of Madagascar. The island of Mauritius, being of volcanic origin, remained uninhabited until the 16th century and became colonised by the French and afterwards by the British. In 1968, the country gained its independence and had a population of about 600,000 inhabitants. Around 50 years later, the population size has doubled, however, despite a growing population Mauritius has seen a negative urban growth. Being limited in size and with an increasing population, a negative urban growth of the island seems to be inconsistent. Therefore, revisiting the urban definition used in Mauritius was important to counteract the threats posed by unsustainable urbanisation. The research took into account the population statistics of different areas of the island. It was observed that population size, density and quality of life is growing outside the limits of legally defined urban areas which means that rural areas are urbanising in Mauritius. Three villages were identified to be urban, namely Triolet, Goodlands and Saint Pierre. An additional four villages, namely Moka, New Grove, Mahebourg and Le Hochet were found to be at the fringe of urbanisation. Acknowledging the urbanisation of these areas is primordial for sustainable urbanisation as it allows for decentralisation of such areas, whereby, they can have their own administration and budget to tackle environmental and social issues.

Keywords: Mauritius, urbanisation.
\end{abstract}

\section{INTRODUCTION}

The urban population of the world has grown rapidly from 751 million in 1950 to 4.2 billion in 2018 [1]. Cities and towns have existed for 6000 years BC or more. The earliest recorded cities were developed for several reasons which included commercial, religious and political factors; however, the share of the urban population remained low fluctuating between $4 \%$ and $7 \%$ up to until 1850 [2]. After that period, the industrial revolution occurred which changed the shape of urbanisation, by creating favourable environment for urban growth through mass production and enhancement in transport and communication systems.

Apart from changes in the industry, the industrial revolution brought changes in technology, science, military science, education and others. This created a need for multiple functions in one place as compared to rural areas, where only skills for agriculture may have been required. These multi-needs led to high population densities and migration into urban areas, eventually leading to urban growth. Thus, by default, urban areas display concentrated human habitation areas and altered land use compared to rural areas, which is visible even from space.

In addition to a completely different landscape, urban areas are complex systems where the inhabitants have a unique relationship with economic and social activities [3], [4]. Urbanisation also has a huge impact on the environment and climate change, ranging from damages to the ecosystems, biodiversity, water sheds to emissions of greenhouse gases, if unsustainable urban growth occurs.

Urbanisation is becoming increasingly important as the urban areas become larger, numerous, more populated and more complex. Urbanisation without any doubt contributes to the improvement of the quality of life of the urban residents, and is one of the main reasons of global migration trends towards urban areas. Urban residents benefit from better 
infrastructure, higher salaries and improved productivity compared to rural residents [5]. Cities even contribute to reduce rural poverty by increasing the demand for labour, the demand for rural goods, migration and fund transfers to rural areas [6], [7].

However, if urbanisation is not planned carefully, it leads to unsustainable growth causing detrimental impacts on the environment and climate such as water pollution, air pollution, huge waste production, high energy consumption and emissions. Apart from impacts on the environment, Krass [8] identified social, political and economic risks and disadvantages, that urbanisation have in south east Asian cities. Mass unemployment, exploitation of labour, informal and illegal settlement on environmental sensitive land, wide disparities between the poor and the rich and imbalanced representation of the general public; are among the risks of unsustainable urbanisation.

Apart from these risks identified, urban areas are themselves faced with external vulnerabilities such as extreme weather events and sea level rise for coastal cities. Currently, Mauritius is already facing the impact of climate variability and extreme weather events. Average temperature across the island is rising at a rate of $1.5^{\circ} \mathrm{C}$ per decade and even higher rise in temperature has been observed in urban stations. Sea levels are rising at a rate of $2.1 \mathrm{~mm} / \mathrm{yr}$ for the past 10 years at the coast of the main city of Port Louis. Extreme events such as flash floods in the month of February and March have increased, causing disruptions to socio-economical activities and even loss of lives [9]. The national authority for disaster management in Mauritius identified inadequate stormwater drainage in existing and developing regions, backfilling of wetlands and insufficient maintenance of water ways in densely populated areas [10].

\section{URBAN DEFINITION}

Urban area definition from one country to another vary around the world and to such an extent that if superimposed it would be misleading, for example in Turkey; an urban area is a place with a population of 20,000 inhabitants, while in Norway, it is only 200 people [11].

Administrative and legal boundaries are one of the most used definitions around the world to delimit urban areas from rural areas. These delimitations are often defined in the prevailing town and country planning laws as it is the case in Mauritius. These boundaries may be modified after a census and may also require changes in the laws. However, very often censuses are carried out after every 5-10 years and since not all censuses will require amendments to the administrative boundaries, these boundaries can stay static for several decades. Owning to the fact that urban areas are fast growing areas, administrative boundaries often overlook the dynamic nature of these areas and hence are not able to measure the real size of urban areas. China has recently adopted versatile and dynamic urban definitions where villages connected to city or town areas are also defined as urban [12]. Given China's large share of world's population, this definition has changed the scales of world's urban and rural shares.

Population size is another common way of defining urban areas. However, the range of population size is also very wide spread starting from 200 inhabitants as in the case of Greenland; up to 50,000 inhabitants which is used in Japan [11]. These values are highly dependent on the overall country population. The population size criterion is similar to administrative boundary criteria as both are based on rigid and physical boundaries that delimitate a locality. Residential areas often grow in the surrounding urban areas, thus, these definitions may end up excluding numerous inhabitants who are functionally part of the city or town in terms of derivation of their livelihoods. Furthermore, population size criterion does not account for economic and social factors. 
High population density is a major characteristic of urbanisation, nevertheless, population density is rarely used as a lone criterion to define urban areas, as shortage of resources can cause high population density in certain rural areas also, for example presence of water may cause a large number of people to settle down in a small rural area or even a densely populated refugee camp. Thus, population density is used in conjunction with other criteria, for example, Canada defines urban areas as places with 1000 or more inhabitants, having a population density of 400 or more per square kilometre [11]. In India, population density is used along with the main economic activity of the locality in defining urban areas [11].

Apart from population related factors, other parameters are also factored in the definition of urban areas, for example in Japan, economic activity is one of the criteria used such that if more than $60 \%$ of the population are engaged in manufacturing, trade or other urban type of business, the area becomes urban [11]. In certain countries, urbanisation is seen in the social dimension; where urban residents are more educated and well-off, which is evident as urban areas have more facilities. These particular characteristics of urban areas attract people to migrate towards them, especially in large developing countries such as China and India.

As the world becomes more urban, defining urban areas gain more attention both at international and national levels, perhaps because of the iconic moment of the shift from being "rural" to "urban". Although, urban scholars agree that "urban" means more than population size and/or density, the idea of relatively large, densely populated and well serviced infrastructure developments come to mind when urban areas are thought of.

Urbanisation is also closely related to the change in land use, and due to this characteristic can be remotely sensed using satellite data. One such tool is the CORINE (Coordination of Information on the Environment) Land Cover program, being used to map urbanisation in Europe. A study carried out in Poland using CORINE was able to identify urban sprawl [13]. Thus, remote sensing provides the ability to monitor urban and rural systems at various spatial and temporal scales, making remote sensing one of valuable tools in addressing issues related to sustainable development [14]. However, remote sensing requires high quality satellite imagery (low cloud cover), which was not readily available for Mauritius. In addition, due to the small size of the island, using a polygon of 25 ha to represent one type of land use may lead considerable generalisation. Furthermore, urbanisation in Mauritius is more driven by improvement of quality of life and urban density.

\subsection{The Mauritian context}

Mauritius is a small island located in the south west of the Indian Ocean, about $900 \mathrm{~km}$ east of the island of Madagascar and currently house around 1.3 million inhabitants. Mauritius has seen its population size doubled in the past 50 years, and is one of the top 20 most densely populated countries in the world, which is foreseeable due to its limited size. However, since 2009 , the urban population growth has been reported as negative value, which seems inconsistent with the increase in population. The urban population has decreased by $3 \%$ in the past 30 years. It seems that the urban areas are being depopulated; on the other hand, the population size is increasing. With limited land resources, it is obvious that the rise in population is being absorbed in rural areas, which means that urbanisation is occurring outside the legally defined urban areas. This type of accidental urbanisation is often unplanned and leads to unsustainable growth.

The island of Mauritius is divided into nine districts which house the urban and rural areas. As to date, five urban areas are legally recognised, namely the main administrative city of Port Louis, and four towns; Beau Bassin-Rose Hill, Vacoas-Phoenix, Curepipe, and Quatre 


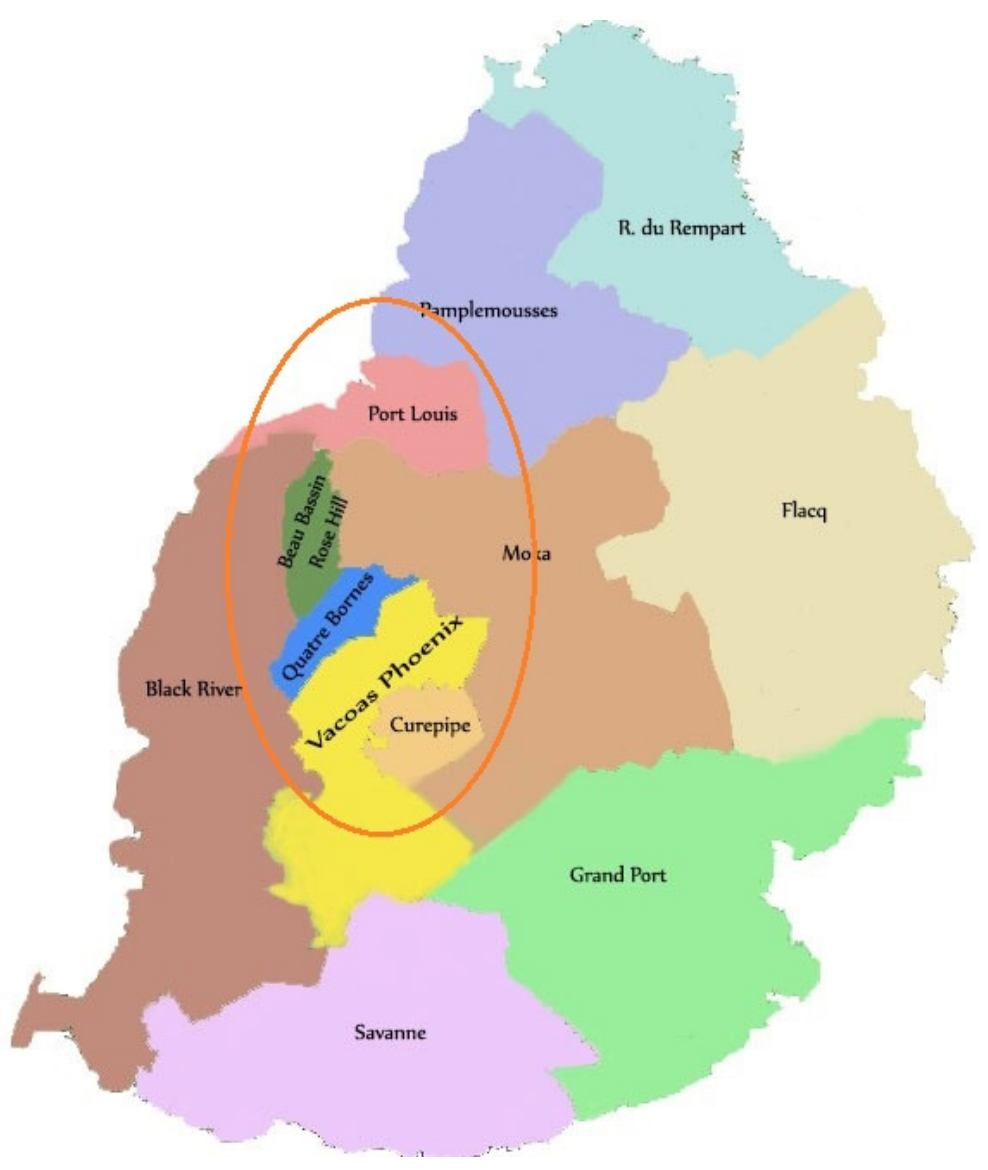

Figure 1: Urban areas in Mauritius.

Bornes. These urban areas are administered under their individual municipal council, while the villages council areas (VCAs) are administered by the District council in which they are situated. With the exception of Port Louis, the four towns are primarily located in the district of Plaine Wilhems. Fig. 1 shows the geographical location of urban areas in Mauritius.

Mauritius uses the administrative tool to define urban areas, that is legally defined boundaries for urban areas without due consideration of the dynamics of urbanisation. The legal tool for defining these boundaries is set in the Local Government Act 2011 [15]. These boundaries have remained almost the same since 1980, that is for nearly four decades, during which the population size has grown by $30 \%$ [16]. During the same period, urban population grew steadily, peaking in the years 2008-2009 and started to decline thereof [1].

The island of Mauritius is $1864 \mathrm{~km}^{2}$ in size and has an overall population density of 623 inhabitants per $\mathrm{km}^{2}$ per area of land [1]. The population density has been increasing, almost doubling since 1970 and is even higher than the world's most populous middle income countries such as India and Nigeria. Some of the urban areas such as Beau Bassin/Rose Hill in Mauritius are even more densely populated than the megacities such as Shanghai and Lagos where population density is $3,800 \mathrm{p} / \mathrm{km}^{2}$ and $3,200 \mathrm{p} / \mathrm{km}^{2}$ respectively [1]. The reason for the high population density is the limited amount of land resources available. 
In addition to a shrinking urban population size, a decrease in the population density in urban areas has been observed between the two recent population censuses as shown in Table 1.

Table 1: Population density of urban areas for the last three censuses [16].

\begin{tabular}{|l|c|c|c|}
\hline \multirow{2}{*}{ Urban area } & \multicolumn{3}{|c|}{ Population density $\left(\mathrm{p} / \mathrm{km}^{2}\right)$} \\
\cline { 2 - 4 } & 1990 & 2000 & 2011 \\
\hline City of Port Louis & 3,108 & 3,265 & 2,959 \\
\hline Beau Bassin/Rose Hill & 4,547 & 5,137 & 5,111 \\
\hline Quatre Bornes & 3,303 & 3,164 & 3,207 \\
\hline Curepipe & 3,068 & 3,339 & 2,946 \\
\hline Vacoas/Phoenix & 1,890 & 1,856 & 1,947 \\
\hline
\end{tabular}

The growing population size and density of the island depicts another picture which could mean urbanisation is occurring outside the legally defined urban boundaries, which need identification.

Identifying the urban areas early on will help with sustainable development through decentralisation. All the VCAs in a district share the same agenda and budget because they are being administered through District Councils. Little or no particular attention is given to the specificity of an area, for example, a coastal high density VCA will have the same share of budget as an inland VCA; despite the fact that the risks faced by a coastal VCA are higher. Administrative and financial decentralisation allows such areas to have more independence in local decision making. This type of decentralisation will help to focus on major issues in these areas such as urban flood which is more hazardous due to high population density. Decentralisation will also allow such areas to have their own facilities, reducing the demand for commuting for services and reducing the pressure on congested urban services.

Recently, Mauritius has launched a smart city development scheme with a view of developing self-sufficient sustainable cities which will improve the wellbeing of inhabitants [17]. These smart cities are being built on undeveloped land in rural areas. It becomes more important thus to recognise urbanising areas such that they can be integrated in those smart cities to ensure inclusive growth and eliminating any disparity between these regions.

At a national level, the formal recognition of urban and urbanising areas allows for enhanced land use and resource planning, improved monitoring of biodiversity and opportunities to drive investment and reduce poverty in such areas. This paper focuses on using demographic data to identify urban and urbanising areas other than the currently defined ones in Mauritius.

\section{METHODOLOGY}

\subsection{Population size}

As mentioned earlier, population size is the most used criteria for defining urban population in the world. In Mauritius, according to the most recent census of 2011, it was observed that all the five existing urban areas had more than 50,000 inhabitants. Data from the past four censuses show that all the legally defined urban areas had a population more than 20,000 inhabitants since 1983; while it is only in the year 2000 that the VCAs started to have more than 20,000 inhabitants as shown in Table 2. 
Table 2: Number of inhabitants in urban and rural areas in Mauritius [16].

\begin{tabular}{|l|c|c|c|c|}
\hline & \multicolumn{4}{|c|}{ Census year } \\
\hline Range of inhabitants & 1983 & 1990 & 2000 & 2011 \\
\hline Number of urban areas & 5 & 5 & 5 & 5 \\
\hline 100,000 or more inhabitants & 1 & 1 & 3 & 3 \\
\hline $50,000-99,999$ inhabitants & 1 & 4 & 2 & 2 \\
\hline $20,000-49,999$ inhabitants & 3 & - & - & - \\
\hline Less than 20,000 inhabitants & - & - & - & - \\
\hline Number of village council areas (VCAs) & 93 & 124 & 124 & 124 \\
\hline 20,000 or more inhabitants & - & - & 1 & 2 \\
\hline $10,000-19,999$ inhabitants & 9 & 9 & 13 & 17 \\
\hline $5,000-9,999$ inhabitants & 24 & 29 & 34 & 33 \\
\hline $3,000-4,999$ inhabitants & 23 & 29 & 25 & 27 \\
\hline $2,000-2999$ inhabitants & 16 & 27 & 29 & 26 \\
\hline $1,000-1,999$ inhabitants & 23 & 25 & 19 & 16 \\
\hline $500-999$ inhabitants & 2 & 4 & 2 & 2 \\
\hline $200-499$ inhabitants & 1 & 1 & 1 & 1 \\
\hline Less than 200 inhabitants & - & - & - & - \\
\hline
\end{tabular}

Based on the above data, it has been proposed that a population size of above 20,000 inhabitants should be a cut-off limit to categorise an area as urban. Although population size does not fully reflect the dynamics of urbanisation, owing to the small size of Mauritius, it is thought to be a good criterion, without exuberating urbanisation trends, as high population size will inevitably lead to a high population density.

\subsection{Population density and quality of life}

For VCAs that have a population size of less than 20,000 inhabitants, an additional criterion was proposed based on population density and quality of life; that is VCAs having a population size above 15,000 inhabitants, a population density of above $1000 \mathrm{p} / \mathrm{km}^{2}$ and a Relative Development Index (RDI) of above 0.7945. The RDI is an index computed by the Central Statistics Office of Mauritius, mainly, for the ranking of administrative areas in terms of integrated development. The index itself is a composite of the following variables [16]: (1) Percentage of households having piped water, Percentage of households having electricity, (2) Percentage of households having flush toilet, (3) Percentage of households living in dwellings made of concrete, (4) Percentage of households having one or more rooms used for living purposes per person, (5) Percentage of households who own their dwelling, (6) Percentage of population aged 18 years and over having at least School Certificate or equivalent educational attainment, (7) Primary Enrolment Ratio, (8) Secondary Enrolment Ratio, (9) Literacy Rate of The Population Aged 12 Years and Over, (10) Employment Rate of The Population Aged 12 Years and Over, (11) Percentage of the employed population in occupational groups 1, 2 and 3 of the International Standard Classification of Occupations (ISCO), i.e. legislators, senior officials and managers; professionals; and technicians and associate professionals.

In order to choose the cut-off point between rural and urban, the average value of RDI displayed by the urban areas was calculated. The average value was found to be 0.7945 based on 2011 census data, thus, this value is taken as delimiting RDI value for urban and rural 
areas. Since urban areas are also associated with high population density, a value of $1,000 \mathrm{p} / \mathrm{km}^{2}$ was also chosen to identify urban areas with population size above 15,000 inhabitants but less than 20,000 inhabitants.

\subsection{Working definition of urban areas}

A working definition has been proposed to identify urban areas, other than the legally defined one as follows:

"An urban area is:

1. A village council area with a population above 20,000 inhabitants or;

2. A village council area with a population above 15,000 inhabitants with a relative development index above or equal to the average relative development index of the existing urban areas and a population density above $1000 \mathrm{p} / \mathrm{km}^{2}$.

The process for identification used in this paper is given in Fig. 2.

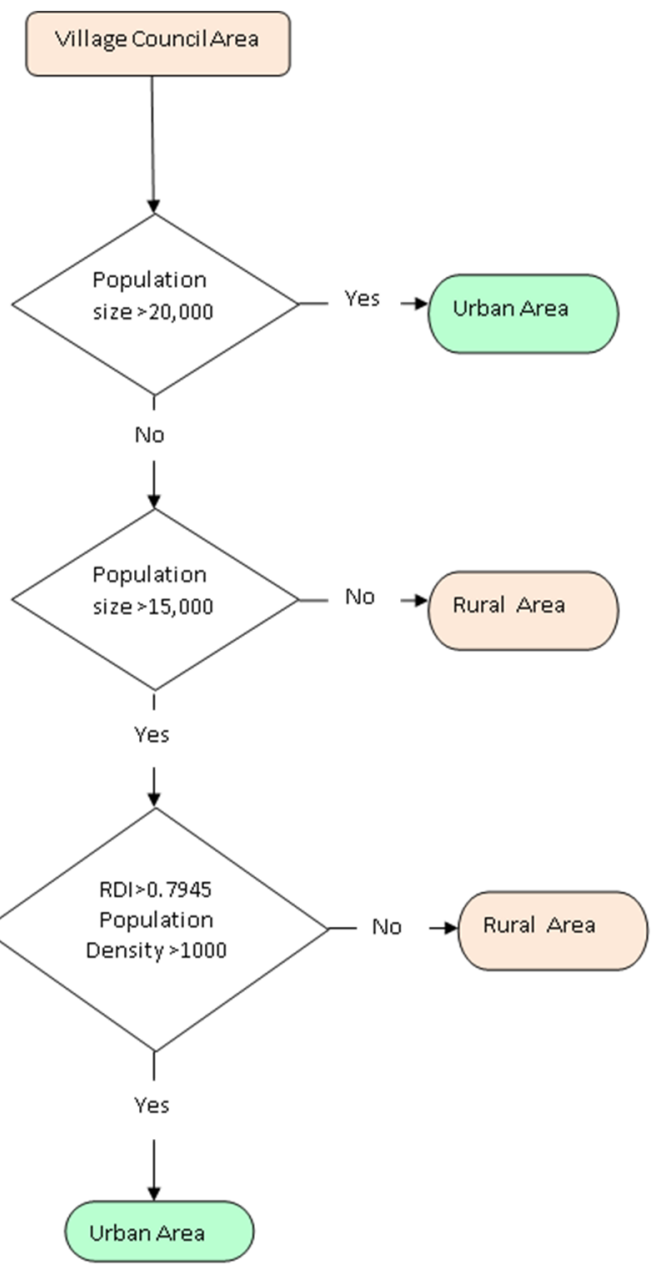

Figure 2: Proposed process for Identification of urban areas. 


\section{RESULTS}

When the population size criterion of above 15,000 inhabitants was applied, eight VCAs were found to have more than 15,000 inhabitants, out of which two had more than 20,000 inhabitants as shown in Table 3. These two VCAs are namely Triolet and Goodlands, qualify to be urban based on the above 20,000 inhabitants criterion. These two villages are located in the north of the island.

Further screening was done for the remaining six VCAs based on the population density and RDI criteria to determine if they could qualify as urban. Only one VCA, namely St Pierre, was found to have an RDI above the urban areas average, that is, 0.7945 as shown in Table 4.

Table 3: VCAs with population size above 15,000 inhabitants [16].

\begin{tabular}{|c|l|c|}
\hline SN & VCA & $\begin{array}{c}\text { Population size/ } \\
\text { inhabitants }\end{array}$ \\
\hline 1. & Triolet VCA & 23,386 \\
\hline 2. & Goodlands VCA & 20,712 \\
\hline 3. & Bel Air Riv. Sèche VCA & 17,605 \\
\hline 4. & St Pierre VCA & 15,982 \\
\hline 5. & Centre de Flacq VCA & 15,791 \\
\hline 6. & Bambous VCA & 15,345 \\
\hline 7. & Mahébourg VCA & 15,176 \\
\hline 8. & Le Hochet VCA & 15,034 \\
\hline
\end{tabular}

Table 4: RDI and population density of selected VCAs [16].

\begin{tabular}{|c|l|c|c|}
\hline SN & VCA & RDI & Population density \\
\hline 1. & Bel Air Riv. Sèche VCA & 0.7182 & 970.0 \\
\hline 2. & St Pierre VCA & $\mathbf{0 . 8 1 0 0}$ & $\mathbf{1 , 2 2 3 . 7}$ \\
\hline 3. & Centre de Flacq VCA & 0.7743 & 779.0 \\
\hline 4. & Bambous VCA & 0.6545 & 702.9 \\
\hline 5. & Mahébourg VCA & 0.7661 & $6,775.0$ \\
\hline 6. & Le Hochet VCA & 0.7650 & $2,778.9$ \\
\hline
\end{tabular}

It can be observed that two of the VCAs namely Mahebourg and Le Hochet have a very high population density but have a lower RDI than the set criterion, therefore, was not identified as urban. However, attention also should be given to such areas as they will surely become urban in the near future as the overall island RDI has been improving. Thus, it is expected that the RDI of such areas also will increase soon.

Having a closer look at the most developed VCAs in the island as shown in Table 5; it can be observed that New Grove and Moka should be considered as urbanising areas as they have a growing population size and density.

The 12 parameters used to calculate the RDI were also studied for these seven regions and compared with the most developed area of the island, that is, ward 2 of the Quatre Bornes Town which has an RDI value of 0.8925 . Little difference was found in terms of services available in these areas, however, a noticeable difference was found in terms of education level and type of employment by inhabitants. Moka VCA had similar characteristics as Quatre Bornes Town with high level of infrastructure and large portion of inhabitants having 
Table 5: Most developed VCAs of the island [16].

\begin{tabular}{|c|l|c|c|c|}
\hline SN & Village & RDI & $\begin{array}{c}\text { Population } \\
\text { density }\left(\mathrm{p} / \mathrm{km}^{2}\right)\end{array}$ & $\begin{array}{c}\text { Population size } \\
\text { (inhabitants) }\end{array}$ \\
\hline 1. & Triolet VCA & 0.8002 & $1,574.8$ & 23,386 \\
\hline 2. & St Pierre VCA & 0.8100 & $1,223.7$ & 15,982 \\
\hline 3. & New Grove VCA & 0.8030 & $1,895.1$ & 10,518 \\
\hline 4. & Moka VCA & 0.8715 & 507.2 & 8,846 \\
\hline 5. & Brisée Verdière VCA & 0.8043 & 482.2 & 7,512 \\
\hline 6. & Long Mountain VCA & 0.8093 & 508.4 & 6,995 \\
\hline
\end{tabular}

Table 6: Urban population based on census 2011 data.

\begin{tabular}{|l|c|}
\hline Year & 2011 \\
\hline Total inhabitants & $1,196,383$ \\
\hline Urban inhabitants (administrative boundary) & 499,349 \\
\hline Triolet & 23,386 \\
\hline Goodlands & 20,712 \\
\hline St Pierre & 15,982 \\
\hline Total urban & 559,429 \\
\hline Percentage urban (based on administrative boundary) & $42 \%$ \\
\hline Percentage urban (based on population size) & $47 \%$ \\
\hline
\end{tabular}

higher education and professional employments of around 50\% compared to around $25 \%$ in the other areas. These two areas also had bigger houses.

From the above data, three VCAs have been identified as urban, namely, Triolet, Goodlands and St Pierre and an additional four urbanising areas have been identified namely Moka, New Grove, Mahebourg and Le Hochet. Finally, the urban population has been estimated to $47 \%$ instead of $42 \%$ (Table 6 ) when administrative and legal boundary criteria are applied. These data are evidence that urbanisation of rural areas is occurring in several parts of the island, hence, negating the perception of de-urbanisation in Mauritius.

If the above process is coupled with appropriate remote sensing tools (smaller polygons for training areas), mapping of urbanisation in Mauritius can be done in a real time scale that is as and when its occurring.

\section{CONCLUSION}

Mauritius is a small island with a growing population size and density, however, is showing a negative urban growth. This paper has reviewed the current urban definition used, and based on demographic data has proposed another working definition to identify other urban and urbanising areas. The proposed definition classifies an area as urban if the population size is above 20,000 inhabitants or if population size is less than 20,000 but above 15,000 , and having a population density of above $1,000 \mathrm{p} / \mathrm{km}^{2}$ together with an RDI above 0.7945 . When the definition was applied, three VCAs were identified as urban, namely, Triolet, Goodlands and St Pierre and an additional four urbanising areas were identified namely Moka, New Grove, Mahebourg and Le Hochet. The additional urban areas would lead the urban population to increase to $47 \%$. These data are evidence of urbanisation occurring in rural areas, thus particular attention should be given to these areas and future smart cities to ensure sustainable and inclusive development. 


\section{ACKNOWLEDGEMENT}

This work was carried out as part of the $\mathrm{PhD}$ research project "An Adaptive Approach to Low Energy Sustainable Buildings in the Urban Areas and Future Smart Cities in Mauritius", funded by the Planet Earth Institute Mauritius.

\section{REFERENCES}

[1] World Bank, Urban Population growth, 2018. https://data.worldbank.org/indicator/ SP.URB.GROW?end=2017\&locations=MU\&start=1960. Accessed on: 14 Sep. 2018.

[2] Lowry, I., World urbanization in perspective. Resources, Environment and Population: Present Knowledge, Future Options, eds K. Davis \& M. Bernstam, Oxford University Press: New York, pp. 148-176, 1991.

[3] Fragkias, M., Islam, S. \& Sprague, C., Modeling teleconnected urban socialecological systems: Opportunities and challenges for resilience research. International Journal of Urban Sustainable Development, 9(2), pp. 207-225, 2017.

[4] Pitman, A.J., On the role of geography in earth system science. Geoforum, 36, pp. 137148, 2005.

[5] Browne, E., Benefits of urbanisation in Asia. GSDRC Helpdesk Research Report No 1082, 2014.

[6] Hilderband, M., Kanaley, T. \& Roberts, B., Sustainable and inclusive urbanisation in Asia Pacific, UNDP Strategy Paper, 2013.

[7] Mathur, O.P., Urban Poverty in Asia, 2013.

[8] Krass, F., Megacities and global change in east, south east and South Asia. Asien, 103(4), pp. 9-22, 2007.

[9] Mauritius Meteorological Services, Climate of Mauritius. http://metservice.intnet.mu/ climate-services/climate-of-mauritius.php. Accessed on: 3 Feb. 2020.

[10] Ministry of Social Security, National solidarity and environment and sustainable development. Government response to mitigate the impact of flooding, 2019.

[11] United Nations, World Urbanisation Prospects, United Nations: New York, 2017.

[12] Kamal-Chaoui, L., Leman, E. \& Rufei, Z., Urban trends and Policy in China. OECD Regional Development Working Papers, 2009.

[13] Cieslak, I., Bilozor, A. \& Szuniewicz, K., The use of the CORINE land cover (CLC) database for analyzing urban sprawl. Remote Sensing, 12(2), p. 282, 2020.

[14] Avtar, R. et al., Assessing sustainable development prospects through remote sensing: A review. Remote Sensing Applications: Society and Environment, 100402, 2020.

[15] Republic of Mauritius, The Local Government Act 2003 Act No 32 of 2003, 2003.

[16] Central Statistics Office, Census 2011. http://statsmauritius.govmu.org/English/ CensusandSurveys/Pages/census/Census-2011.aspx. Accessed on: 21 Sep. 2018.

[17] Economic Development Board Mauritius, Smart City Scheme, 2017. www.edbmauritius.org/schemes/smart-city-scheme/. Accessed on: 3 Mar. 2019. 